\title{
United States war veterans gain access to medicinal marijuana
}

Previously published at www.cmaj.ca

$\mathrm{T}$ he military culture and the counterculture once stood apart across a great divide in the United States, one side waving red, white and blue, the other side letting its freak flag fly - often through a cloud of cannabis.

Times change.

The US Veterans Affairs Department is quietly embracing old soldiers who use marijuana for pain and infirmity. Under a new directive, health care provided to veterans by the federal government will no longer be at risk if they use medicinal marijuana in states where it is legal.

Medicinal marijuana falls into an odd limbo in the US, forbidden coast to coast under federal statute, yet sanctioned by 14 states and counting.

To deal with this contradiction, President Barack Obama's administration has effectively shelved the federal law, only prosecuting cases that run afoul of state laws. Now with the Veterans Affairs directive, Washington has essentially agreed to turn a blind eye to medicinal marijuana use by patients under the department's own care.

"He took the heat off this issue," Michael Krawitz, executive director of Veterans for Medical Marijuana Access, says of the president. "It's got to be uncomfortable at the bureaucratic level to make a statement like this. But this is something that needed to be done.'

The VA directive still leaves medical pot in a less permissive environment than in Canada, where court rulings forced the federal government to develop medicinal marijuana regulations that allowed the weed to be used by patients if they obtained physician approval. Military veterans now can have their supplies paid by Ottawa.

But for the US, it's part of a slow, broad shift away from the old cultural ramparts erected in the 1960s and 1970 s by the conservative "silent majority" and the tie-dyed, antiwar masses on the left.

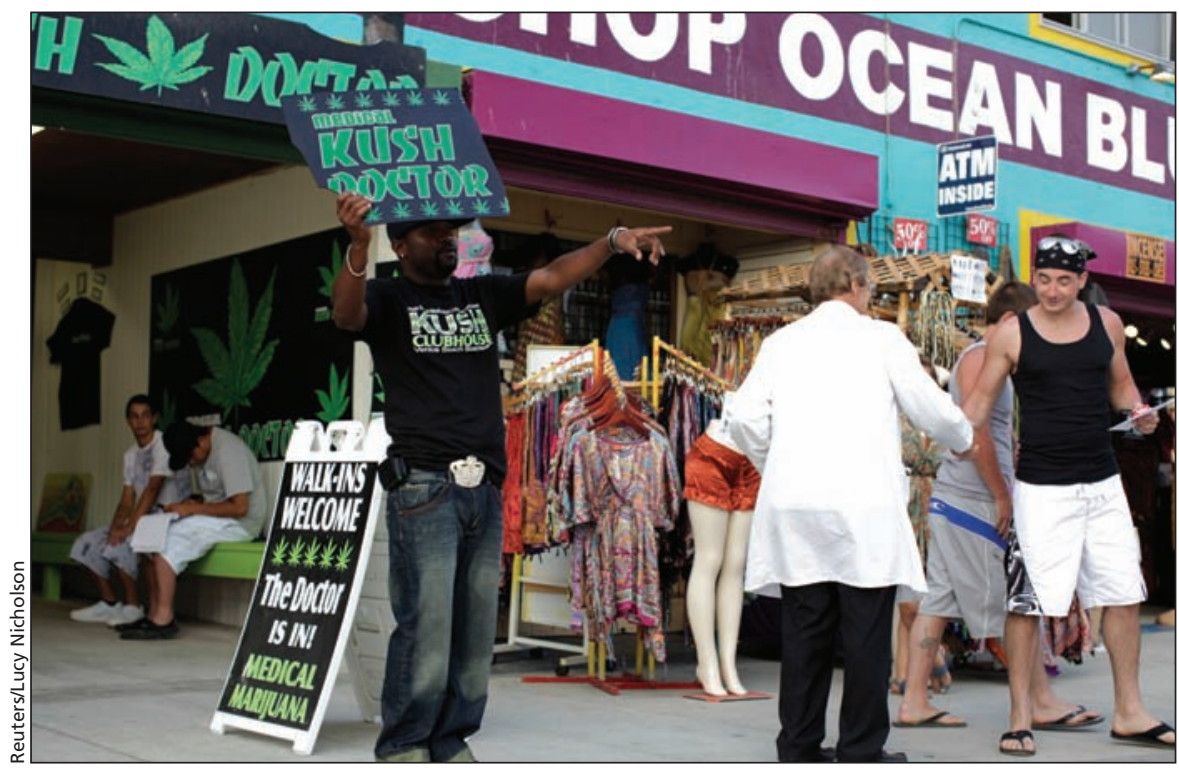

A medical marijuana doctor shakes hands with a man outside a medical marijuana dispensary on Venice Beach in Los Angeles, California.

More than 150 years after the California Gold Rush, California leads the "Green Rush" as the first state to legalize medicinal marijuana, is a powerhouse producer of illicit and legal cannabis, and is home to proliferating storefront pot dispensaries and co-operatives. In November, Californians will vote on a groundbreaking initiative to make marijuana legal for recreational use while voters in several other states decide whether to expand medicinal marijuana.

Mainstream opinion polls find that Americans - even conservative Republicans - now believe marijuana offers genuine medical benefits for some patients and should be legal for that purpose. Public support is not there, however, for outright legalization.

In February, a research centre established by the California legislature in 2000 reported on the first clinical trials in more than 20 years on the medical benefits of marijuana. The centre concluded pot is effective in reducing pain caused by various neurological injuries and illnesses and in controlling muscle spasms associated with multiple scle- rosis (www.cmcr.ucsd.edu/CMCR _REPORT_FEB17.pdf). Relief was found to be comparable to that from antidepressants and medications commonly prescribed for neuropathic pain.

Krawitz was stationed in Guam with the Air Force in the mid-1980s when he had a motorcycle crash in the line of duty, requiring more than a dozen surgeries and untold pain medications. "A fellow patient handed me the butt end of a marijuana cigarette," he recalls. "I thought, maybe I'll get a little high and feel good for a minute, like you've had a cognac or something."

"What I experienced was different. I experienced relief. I was a mess and for the first time in months I felt relief. At that moment, it was a new relationship with that plant."

That was early in the US "war on drugs," when penalties stiffened for illicit drug use across the board and authorities even dared hope they could eradicate marijuana worldwide. Government, says Krawitz, was running "scared of Ma and Pa America."

Acceptance of pot as a salve for pain came gradually, starting with Califor- 
nia's decision to legalize it for that purpose in 1996.

In 1999, the Institute of Medicine reported "a potential therapeutic value for cannabinoid drugs," particularly for pain relief, control of nausea and appetite stimulation (http://books.nap .edu/openbook.php?record_id $=6376 \&$ page $=\mathrm{R} 1)$. That study said the benefits are modest, often surpassed by other medications and associated with "a powerful drug with a variety of effects." Still, it found the adverse effects to be within the range tolerated for other medications for certain patients.

Now, the federal government's nuanced shift on medicinal marijuana enforcement comes as little surprise, given Obama's stance in the 2008 presidential campaign.

"I think the basic concept of using medical marijuana for the same purposes and with the same controls as other drugs prescribed by doctors - I think that's entirely appropriate," he said then.

He further vowed: "I would not have the Justice Department prosecuting and raiding medical marijuana users.'

Obama, 49, is a child of the 1960s but not of the counterculture: He was only six when Woodstock happened. Yet his generation had plenty of exposure to drugs, and he has acknowledged using marijuana and cocaine in his youth to "push questions of who I was out of my mind." His predecessor in office, George W. Bush, routinely cracked down on medical marijuana purveyors, regardless of state law, and maintained restrictions on veterans that Obama is only now relaxing.

Veterans Affairs policy had stated that patients treated at VA hospitals and clinics could be denied pain medication if they were found in drug testing to have used an illicit substance.

Now, says Dr. Robert A. Petzel, the
VA's undersecretary for health, "if a veteran obtains and uses medical marijuana in a manner consistent with state law, testing positive for marijuana would not preclude the veteran from receiving opioids for pain management" in a VA facility.

Washington's decision to let state laws take precedence eases matters for patients but leaves patchwork rules in place.

Only New Mexico, for example, explicitly allows people with posttraumatic stress syndrome - a common condition of veterans returning from the Iraq and Afghanistan wars - to use medical marijuana. California doctors can recommend medical marijuana for any illness for which pot provides relief. Other states are more restrictive. - Cal Woodward, Washington, DC

DOI:10.1503/cmaj.109-3334

\section{Patient charters all buzz and no bite, advocates say}

Previously published at www.cmaj.ca

$\mathrm{P}$ atient groups are skeptical that a national charter of patient rights would reap real-world changes in Canada's health care system.

The Canadian Medical Association's recent proposal that a national patient charter be established in Canada follows on the heels of two decades of efforts to legislate patient rights at the provincial level, a hit-and-miss experience that's left patient groups questioning the necessity of such a document.

It's commonly held that patient charters provide people with a bit of ammunition in dealing with indifferent or stubborn health care bureaucracies, helping them to obtain information about their conditions from health care providers or about medical mishaps.

But the creation of a national charter listed low among health consumer priorities at the Canadian Patient Summit in March, says Karen Philp, chair of the summit and CEO of the Canadian Wound Care Association. "Their attitude was, 'Well that's nice, but let's not spend too much energy on it, and if we could forego the charter altogether and just implement the content, then that would be great.' It just wasn't on the radar."

The summit brought together some 200 people representing more than 30 patient organizations across the country. According to Philp, many participants said a charter should come after, not before Canada tackles more nutsand-bolts changes to system. Drafting a charter any sooner would only "bog down" necessary reform with "a lot of lip service."

Summit participants identified a number of more pressing health care reforms, says Philp, such as reducing wait times, implementing a national catastrophic drug plan and improving access to health care providers and services.

If systemic change doesn't precede the creation of a national charter, implementation will likely be an uphill battle, says Chris Summerville, CEO of the Schizophrenia Society of Canada. "Until you deal with the issues of supply and demand, it's going to be very difficult to honour the spirit of a charter."
The inherent difficulty of implementing a charter from the top down is among the reasons previous attempts to legislate patient rights at the provincial

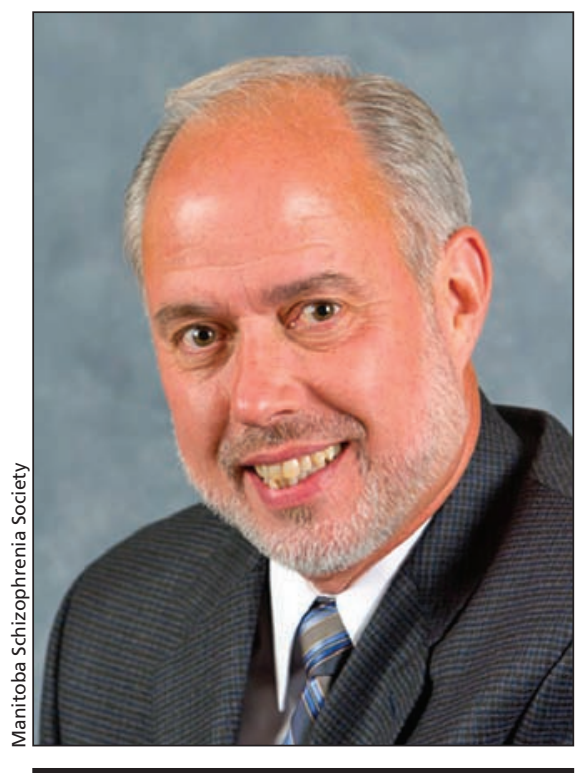

"Until you deal with the issues of supply and demand, it's going to be very difficult to honour the spirit of a charter," says Chris Summerville, CEO of the Schizophrenia Society of Canada. 